\title{
The genetic mechanism of fallness: St. Maximos the Confessor revisited
}

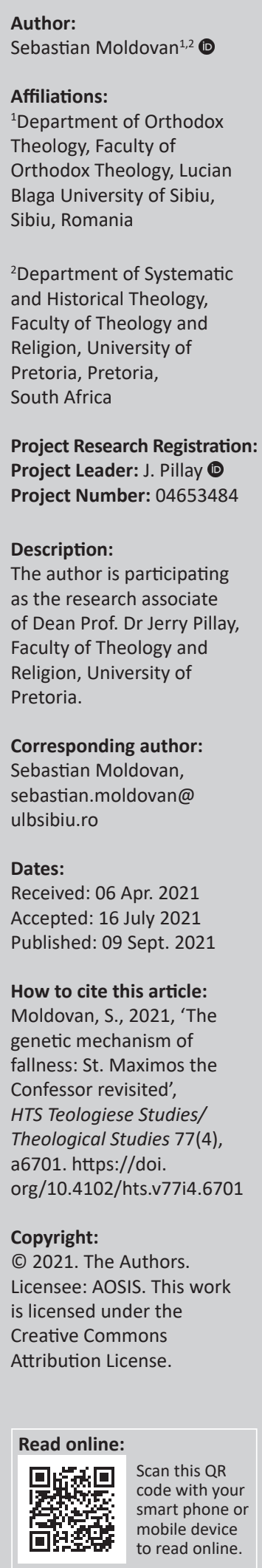

Through a close reading of the two definitions of evil in the Introduction to Responses to Thalassios, this article points out a circular, cognitive-affective-somatic, genetic mechanism that St. Maximos the Confessor considers responsible for the initiation and transmission of the fallness as a human condition and the specific manifestation of it in the form of passions. It elucidates the first definition as mainly phenomenological, by identifying the circular mechanism and its behavioural expressions, and the second definition as more aetiological, by explaining why this mechanism emerges and reemerges with the fallen humanity despite its catastrophic results.

Contribution: This article highlights a double genetic mechanism (survival cum passions) that St. Maximos the Confessor grasped within the fallen human condition as a curse solvable only in Christ, a notion largely carved out by previous Maximian scholarship, but fully explained and valuated here.

Keywords: fallness; passions; philautia; responses to Thalassios; Maximos the Confessor.

\section{Introduction}

This article is part of a series dedicated to the conception of passions in the work of St. Maximos the Confessor, which, in turn, I use as a term of reference in a comparative investigation of the Eastern Patristic conception of passions and contemporary scientific models of addictive behaviours (Moldovan 2018:281-294). The intellectual history of the traditional association and modern dissociation between passions or vices and addictions has already been elaborated in the space of Western Christianity (Cook 2006). Although addressed, the specific contribution the Eastern spiritual anthropology may have to understand a behavioural issue of the magnitude and severity of addictions has so far not benefited from a systematic research. In addition, existing studies of this kind - most dedicated to more general themes, not specific to addictions - have focused mainly on the therapeutic relevance of Christian-Orthodox spirituality, focusing on the issue of recovery, while the etiopathological aspects, the causes and mechanisms of behavioural disorders, and passions for that matter remained less investigated (Cook 2012; Trader 2011). A proper research of them involves, however, the examination of all nosological categories, not only of symptomatology and of therapy. ${ }^{1}$

One reason for this situation may be that in the Eastern spiritual tradition, the description of the manifestations of passions and the therapeutic means necessary for dispassion are very plentiful, whereas the causes and mechanisms of their origin are approached not only much more briefly, but usually 'resolved' by invoking the original episode of the fall. The example of St. Maximos the Confessor (c. 580-662), a simple monk yet famous Byzantine theologian, and his writing Responses to Thalassios $(Q T)$ is a classic in this regard. I will dwell in this article only on the Introduction to this major work of St. Maximos, as a case study, and, more precisely, only on the two definitions of evil that he exposes there. ${ }^{2}$

Towards the end of this text, after a thorough list of the problems of the passions through a long series of questions, each with its own implicit answer, the author declines his correspondent's request to explicitly deal with 'principle, modes and causes' (181-182) (Constas 2018:80) of the

1.I argued the possibility and the relevance of this comparative research in previous studies; see Moldovan (2013, 2016). I am thankful to the anonymous reviewers for their useful comments on this paper.

2.For the Greek text, I use the edition of Sources Chrétiennes (Maxime le Confesseur 2010), with the number of the corresponding lines in the brackets. For the English translation, I use Constas (2018). The abbreviation QT stands for the Latin title, Quaestiones ad Thalassium. It is followed by the number of the responses quoted; Intr stands for the introduction to the work by Maximos himself.

Note: Special Collection: Lucian Blaga University, Sibiu, Romania, sub-edited by Daniel Buda (Lucian Blaga University) and Jerry Pillay (University of Pretoria). 
passions. Maximos offers, nevertheless, a small treatise on their origin, in two successive, brief, and very like explanations of the existence and manifestation of evil. He develops an original interpretation of the fall of the 'first man' and extrapolates its significance to the experience of all his descendants. The critical aspect of the episode is, as we shall see immediately, the disorientation of the ontological relationship between man and his Creator and its substitution with His creatures, as well as the catastrophic existential consequences of this deception. Maximos is not content to say that, as descendants of Adam, we are partakers of his fall - a fellowship variously interpreted in Christian tradition, especially by the exegesis of the famous Romans 5:12, either as a universal sin or guilt or mortality or all together - but consider that the original sin is always active for postlapsarian humanity, through a behavioural mechanism that it triggers and which is reactivated in our lives, of all, with the sole exception of Christ (Larchet 1998).

In the rest of this article, I will examine the two consecutive explanations or definitions of evil, trying to highlight this complex psychological-behavioural mechanism that Maximos considers responsible for the initiation, installation, durability and transmission of the fallness as a human condition and of the passions as a specific manifestation of it. I will then examine this text in comparison with other similar passages in the Responses to Thalassios (hereafter QT), to identify common elements and different aspects, a comparison that shows the general relevance for Maximos' thinking of the mechanism formulated here. Finally, I address the role the two pairs of emotions, namely pleasure and pain, lust and fear, play within this mechanism, and suggest their similarity with the modern concept of affective dysregulation. ${ }^{3}$

\section{The first definition of evil}

Denying evil any ontological consistency, Maximos considers it a deficiency ( $\left.\tilde{\varepsilon}^{\prime} \lambda \lambda \varepsilon i \psi 1 \varsigma\right)$ or, more precisely, a failed attempt at fulfillment. Being launched into existence by the Creator and endowed with a constitutive desire for Him, the first man directed his desire - at the suggestion of the evil one - to the created world, and not to the Cause and Purpose of his existence (218-219), thus engaging him in a movement

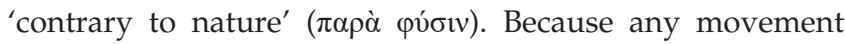
means the activation or use of natural powers - intellectual, emotional, sensorial and somatic - this original movement corresponds, on the cognitive level, to the ignorance of God and the captivity of the knowledge in the visible, sensorial universe; on the affective level, to the generation of the

\footnotetext{
3.Steel (2012:229) remarked the importance of 'close reading' of crucial texts, and $Q T$ Intr is surely such a text. Taking as the aim of this paper to present Maximos par so même, no attention is paid here to the issues of influences on Maximos, nor engage contemporary scholarship more than pointing some relevant reference out. The most recent reading of $Q T$ Intr is offered in the excellent monograph of Summerson (2020;especially 38-46), dedicated to a close treatment of the whole $Q T$. However, it reads the two definitions indistinctly and only from the perspective of their relevance for Maximos' general ascetical hermeneutics in QT. In contrast, of their relevance for Maximos general ascetical hermeneutics in QT. In contrast, my focus is on what Maximos has to say in the two definitions of evil precisely, especially on the fall's two-component genetic mechanism he unfolds here. Fo ground references in Maximian anthropology, see Thunberg (1995), Larchet (1996) and, more generally, Pauline and Bronwen (eds. 2015). Most valuable introductions, comments and references to QT offer Larchet and Constas in the cited edition (supra); Summerson (2020) is also an excellent reference for the preceding tradition on St. Maximos and for secondary literature as well.
}

passions, associated to self-love as love for the body and its pleasure-pain dialectic; and somatically, to the appearance of death as the corruption of the body.

What is remarkable in this text is the detailed description of the implications of this first choice, identifying no less than

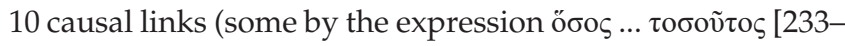
240]) between the various components of the human structure: (1) from the disorientation from the Purpose, to the ignorance (ó $\gamma v 01 \alpha$ ) of God; (2) from ignorance, to the complete occupation of the power of knowledge only with sensible ( $\tau \dot{\alpha}$ $\alpha i \sigma \theta \eta \tau \dot{\alpha}$ ) or visible ( $\tau \dot{\alpha}$ ó $\rho \omega \mu \varepsilon \dot{v} \alpha$ ) things, just like the animals; (3) from this exclusive concern to the sensorial realm, back, to a stronger ignorance of God (closing a first circular

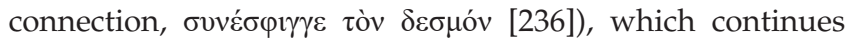
through (4) a more accentuated attachment ( $\dot{\alpha} v \tau \dot{\varepsilon} \chi \omega)$ to the experience of sensorial satisfaction. This first circuit opens another: (5) from the filling of this experience arises the

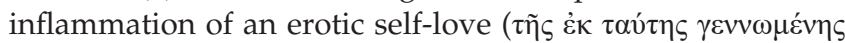

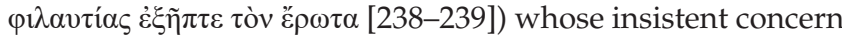
( $\pi \varepsilon \varphi \rho \circ \nu \tau \iota \sigma \mu \varepsilon ́ v \omega \varsigma \pi \varepsilon \rho \iota \varepsilon \pi \circ \imath \varepsilon \tau$ [239-240]) is (6) the invention

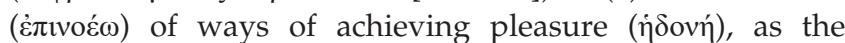
fulfillment of self-love. In this place, there arises a causal link which, although driven by human behaviour, is not the direct product of it, but of Providence, which establishes a corrective

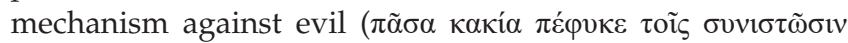

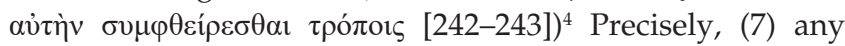

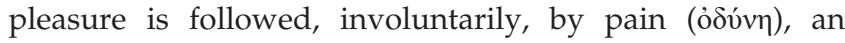

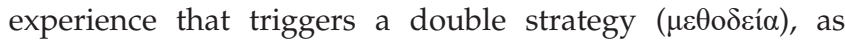
comprehensive (pan-human and lifelong) as it is futile ( $\left.\dot{\alpha} \mu \eta \dot{\chi} \chi v_{0} \varsigma\right),(8)$ to bring pleasure and (9) to avoid pain ( $\pi \rho$ ò $\varsigma$

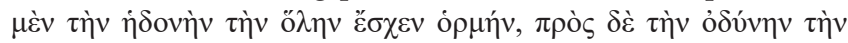
ö $\lambda \eta v \dot{\alpha} \pi$ ориүฑ์ [245-246]), each aspect of the strategy having many specific forms, but there are also (10) mixed, perverse forms $(\mu \circ \chi \theta \eta \rho i ́ \alpha)$, of pleasure-pain; all this reinforces

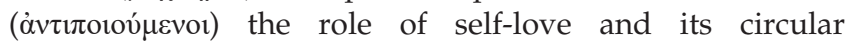
relationship with the dialectic pair pleasure-pain (see Thunberg 1995:156-159; Von Schönborn 1982). ${ }^{5}$ (A graphical summary of this first definition is shown in Figure 1.)

\section{The second definition of evil}

In his characteristic style, Maximos resumes the problem of understanding evil, repeating some points and bringing new ones. This time, in the foreground of the analysis, is no longer the components of the psycho-somatic experience 'against nature', with their circular interdependence and their multiple forms of manifestation in passions, but the paradoxical character of the life alienated ( $\dot{\alpha} \pi \circ \xi \varepsilon v o ́ \omega)$ from God, $^{6}$ namely, how the substitution of the noetic relationship with the Creator on account of the sensorial relationship with the material creation produces a surrogate existence in which what seems to give its consistency is the reason for its essential inconsistency and unhappiness precisely.

\footnotetext{
4.This providential correction is a recurrent theme in Maximos; see, for instance, $Q T 1$ 52,61, Ambiguum 7,8

5.A final link between philautia and ignorance of God is not explicitly stated here but can be inferred from the second definition (342-343; see also 301-303).

6.Also briefly mentioned in the first definition (259-261).
} 


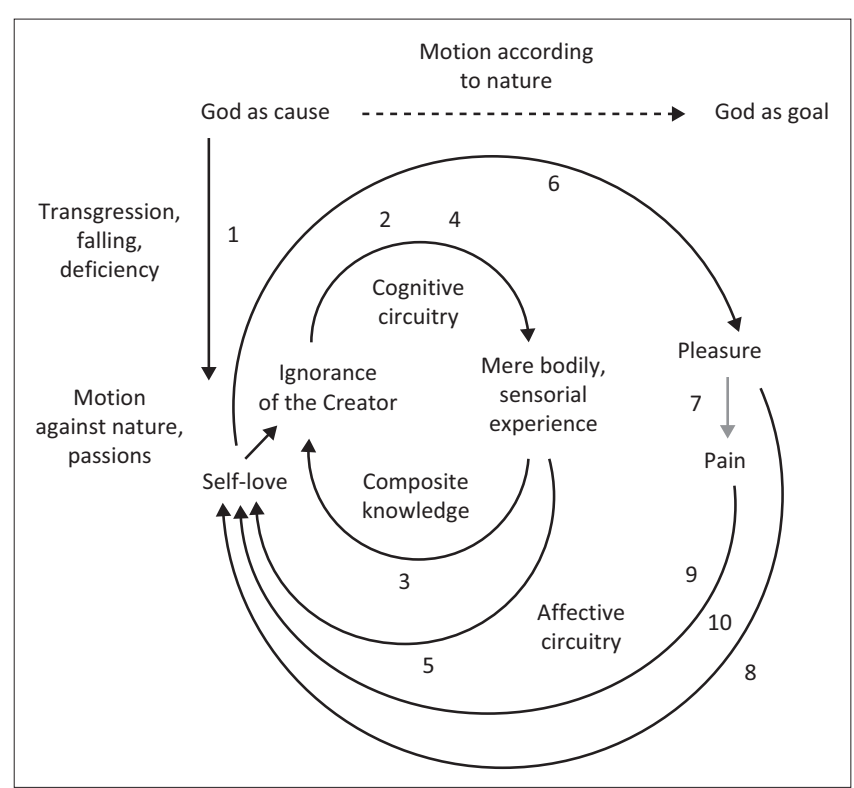

FIGURE 1: The circular mechanisms of the fall (in grey: corrective mechanism).

Maximos identifies three types of substitutions: the worship of God is replaced by the worship of the creature (with direct reference to $\mathrm{Rm}$ 1:20-21, 25), and an authentic knowledge of creation - one in communion with the Creator, in a state of deified being - is replaced by a false knowledge, in which the mind and sensation as powers of knowledge are both

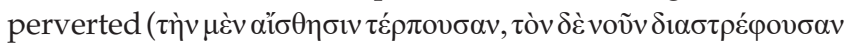
[321-322]). He introduces here a short exegesis to the 'tree of the knowledge of good and evil' (312-336; cf. Gn 2:17; see Constas 2018:86-87, note 53; Oancea 2021), interpreted as the visible universe ( nourishment by it naturally produces the experience of pleasure and pain, therefore a somatic good or evil, as well as because it offers either an epistemological good, through

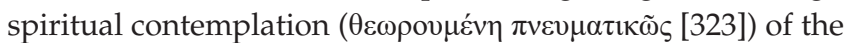
divine reasons of creation, or an epistemological evil, through a bodily knowledge ( $\sigma \omega \mu \alpha \tau \iota \kappa \tilde{\omega} \varsigma)$. The evil that this 'bodily' way of knowing described in the first definition gives rise, consists, he says now, in forgetting $(\lambda \dot{\eta} \theta \eta)$ the divine and

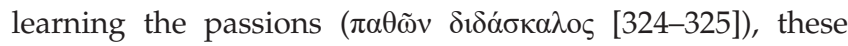
cognitive and affective aspect being linked to each other by

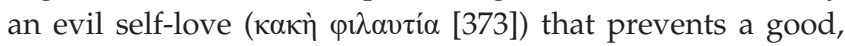

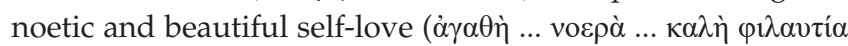
[374-376]). It is precisely the emphasis on philautia and its role that seems to be the main purpose of resuming the definition. ${ }^{7}$

Maximos explains the substitute worship through the experience that material creation sustains man's bodily

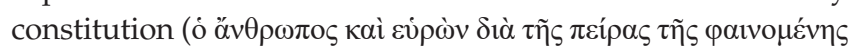

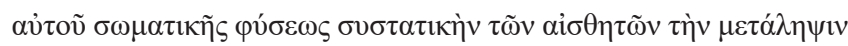
[298-300]), which is as well the reason of the philautia ( $\kappa \alpha \tau$

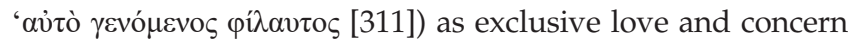
for the body. But why would things be like this? If in the first

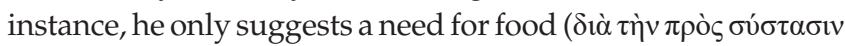

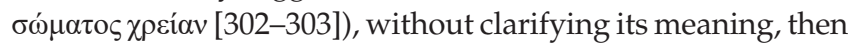

7.1 keep the term untranslated to emphasise its importance here; see Thunberg (1995:232-247). Its absence in parallel texts like QT 21 and 61 may be motivated by Christological focuses (see below). he returns to the idea by introducing into the argument the reality of death as a corrupt life and the struggle for survival. The expression the entire nature of physical bodies is

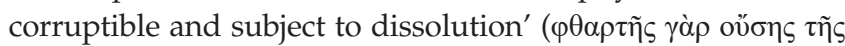

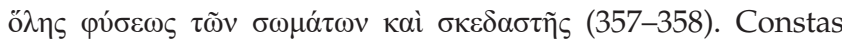
(2018:89) appears as an explanation for a previous statement:

[A]ll who share in human nature possess, according to varying degrees of quantity and quality, a vital and active affection for

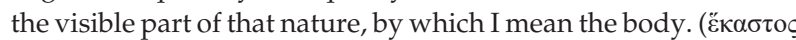

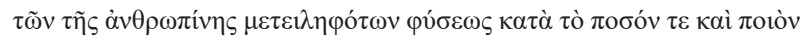

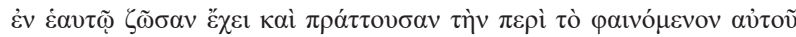

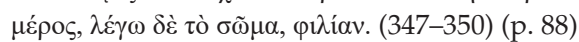

Philautia is, in this sense, a self-love in the conditions of mortality. It is, at the same time, the main determinant of survival strategies and the main result of their inevitable failures, fueling both the fear of death and pain (of course, a symptom of death) and the effort to avoid them in various ways. Or precisely because any effort in this regard is, in the end, in vain and the faithful companion of life ( $\dot{\varepsilon} \lambda \varepsilon \tilde{v} v$

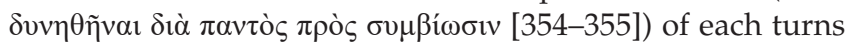
out to be, only the pain, not the pleasure, philautia locks us inexorably into the fatal circularity of a deification without God, of a short-lived survival and of unsatisfactory satisfactions. Continuing the expression quoted above, he says (Constas 2018):

[W] hatever a person does to keep it in a condition of stability, he succeeds only in hastening the body's corruptibility, for out of fear he does not always wish for the object of his desire, but instead, contrary to all sense and his own free will, he pursues what is not desirable through what is desirable, having become dependent on things that by nature can never be stable. $\left(\delta \mathrm{l}^{\prime}\right.$ ' $\sigma \sigma \omega \mathrm{v}$

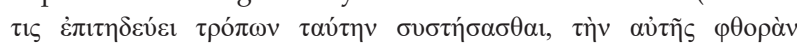

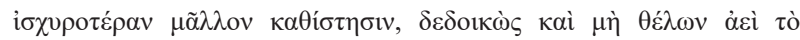

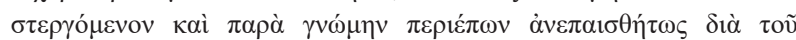

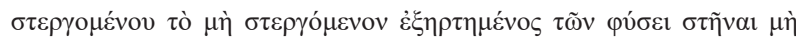

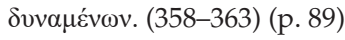

Striking in this sentence is not only the contradiction between philautia and its consequences but also the voluntary $(\pi \varepsilon \rho 1 \varepsilon \dot{\pi} \omega v)$

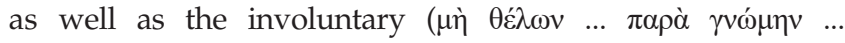

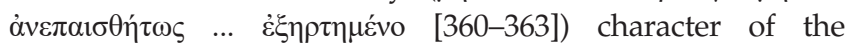
circularity in question. In context, both death and dependence on material creation as a source of survival and care for the body as a personal support of survival are all involuntary. But not only that, despite all these determinations, Maximos categorically asserts the responsibility of each of us, ${ }^{8}$ which implies the possibility of choosing otherwise than in the sense of the mentioned constraints, but what he states is that precisely this freedom is also the cause and the subject of an even more radical constraint, a true bondage, that are the passions, generated by philautia (Constas 2018):

[T] his affection forces man, as if he were a slave, to contrive all

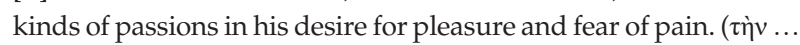

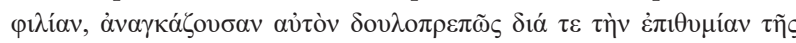

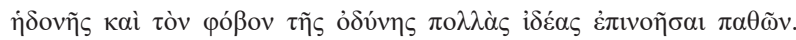
(349-352) (p. 88)

8.Especially by the repeated and uneported transition from the third person, designating Adam, to the first person (plural), designating each of us, as well as through the exhortation style at the end of the text. Maximos also asserts a through the exhortation style at the end of the text. Maximos also asserts a
responsibility not only towards oneself but also to others (392-393), therefore, a role for the education in the formation of passions and the recovery to dispassion as well. 
Two levels of the postlapsarian existence overlap here: the first is that of survival, and the second is that of the passions. It should be noted that, in the case of the first, there is not only a shift from a spiritual life to a biological one but also an alteration of the functioning of all components of the human constitution, intellect, affectivity, sensation and body.

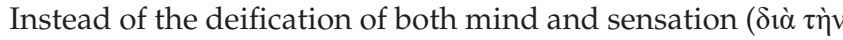

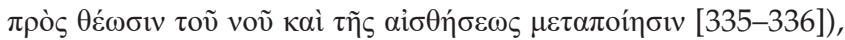
an 'animalization' of them takes place (referring to Ps $48: 12$, 21 [LXX], usual in Patristic tradition) or, as he states in the first definition, a change of the logic of existence from its divine reason, to one even more irrational than that of irrational beings (Constas 2018):

[I]n every possible way acting for, seeking after, and wishing for the very same things as they, and indeed surpassing them in their lack of reason by exchanging natural reason for something

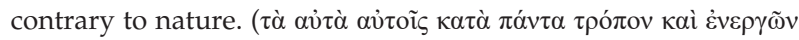

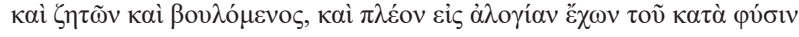

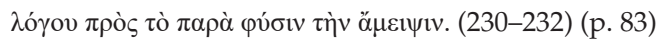

'Against cause/nature' (218/232) is the quintessential expression of irrationality exceeded, that is, of passions, and it derives from the initial irrational movement that misses the

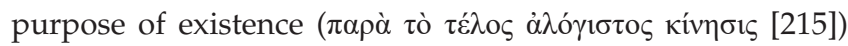
and even surpasses it. We can therefore highlight the causal sequence as follows: original deficient movement > mortality/survival $>$ philautia $>$ passions. Philautia is born from the experience of satisfaction acquired by consuming the material world as supporting somatic life and in turn gives birth to passions, through the mentioned dialectical mechanism pleasure-pain, as a regime of life inferior to simple survival. Note the fact that philautia is not only a kind of instinct of survival, as such involuntary, but also an alteration of what remains voluntary in the postlapsarian condition. Maximos does not insist here on this aspect, but he does not omit it either (Constas 2018):

\begin{abstract}
He is consequently subject to change together with those things that break up and scatter the disposition of his soul, which is ceaselessly tossed about like a ship on a sea of perpetual flux and change, while he himself fails to perceive his own destruction, for the simple reason that his soul is completely blind to the

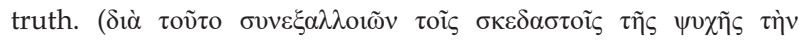

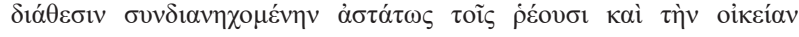

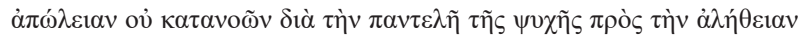

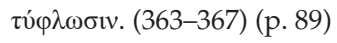

The disposition of the soul ( $\delta \dot{\alpha} \theta \varepsilon \sigma \sigma \varsigma)$ is a central element of the volitional act in Maximian psychology, ${ }^{9}$ and it also appears captured in the circular dynamics of self-destructive philautia, through another important aspect - here only evoked, frequently invoked in the rest of the work - namely the affective dependence on the perishable realities of this world and which is through the satisfactions and dissatisfactions it causes to us, a dominant determinant of human thinking, choice and behaviour. ${ }^{10}$

9.It is only mentioned here, together with a few other technical terms, such as kpiolc

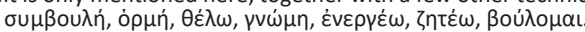

10.This is a fundamental aspect of fallness according to Maximos; see, i.a., QT 48, 51 , 54, 64; Ambiguum 7, 10.42, 45; Capita de caritate, II.92; Capita gnostica, I.5, II.95; Epistles 1, 26; on its antinomic concepts of unity and stability, see Bieler (2019).
In contrast to this dissolution ( $\dot{\alpha} \pi \hat{\prime} \lambda \varepsilon 1 \alpha)$ of life through the incessant corruption ( $\varphi \theta 0 \rho \alpha$ ) of the visible things, including the body, corruption associated with cognitive blindness and affective disorder, it is the natural, stable, permanent

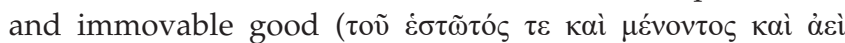

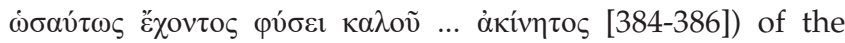
knowledge and love of God who gives true satisfaction and

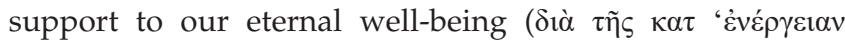

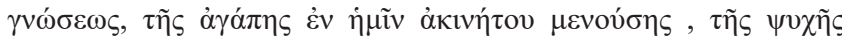

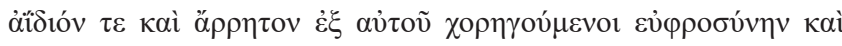

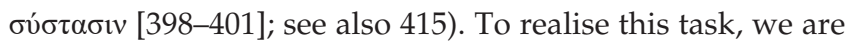
called to follow the path opened by the Savior, who introduces us to a new logic of existence, which offers us liberation from the fallen condition through a series of corresponding separations ( $\dot{\alpha} \pi \alpha \lambda \lambda \alpha \gamma \eta \dot{)})$, point by point opposite to those through which we separated ourselves from God, and their vicious circuits - the attachment to the body, the philautia and its pleasure-pain dialectic, the passions born from here, the sensory veil of ignorance thusly replacing the surrogate existence with the authentic one (see 368-416). ${ }^{11}$ (A graphical summary of the second definition is presented in Figure 2.)

\section{Elucidations and ambiguities}

Several aspects are highly significant in this text from the perspective of the research project carried out. One of them is the triangular relationship man-God-creation, a topos of Maximum thinking. Man's relationship with the Creator and the creation comes permanently out as a problem in the work of Maximos. In particular, the relationship with one's own body seems neuralgic, being involved in the genesis of fallness, philautia and passions (see Cooper 2005). In the text examined here, for example, Maximos presents the relationship between the intelligible and the sensible, respectively, between soul and body, as a polarised one, each of these dimensions of existence generating corresponding forms of life and self-love that are mutually exclusive, which indicates at least a suspicion towards the sensible universe and the body. Moreover, their role seems completely negated when he says, at the end of the Introduction, 'let us be

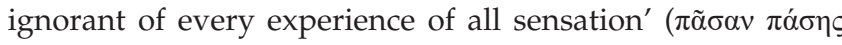

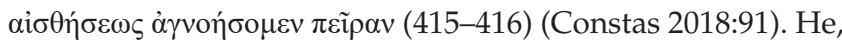
however, refers here to the state of deification (see Larchet 1996)..$^{12}$ Moreover, the antinomically parallel expression from the beginning, 'he completely mixed the whole of his

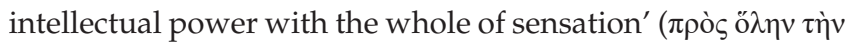

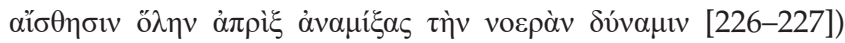
(Constas 2018:83), suggests a legitimate, although not definitive, symbiosis between soul and body, in which the experience of the sensible world does not diminish the relationship with the Creator. Eloquently, in this regard, is Maximos' final recourse to 2 Corinthians 3:18 to illustrate the

11.Although certainly in sight, soteriology, with its aretological and sacramental means, is only alluded in these definitions, in contrast to the similar responses $Q T$ $21,42,61$, where Christ's work and grace take the central place, and all these texts should be read together. More on their comparison below.

12.This seems to be in contradiction with the former statement about the interdiction to know creation until deification (326-336). The issue returns in QT 51 and 59. 


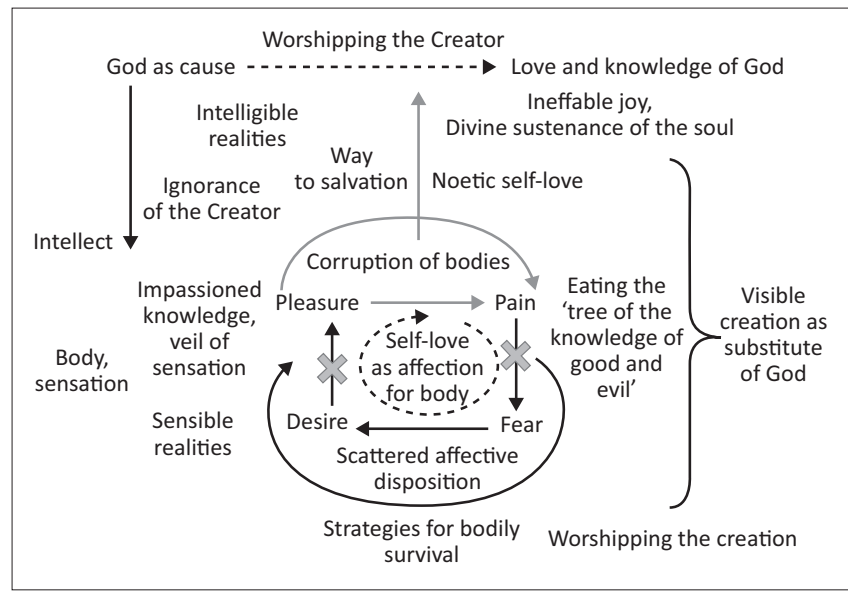

FIGURE 2: The life alienated from God (in grey: corrective mechanisms and soteriological pathways).

contrast between ignoring God because of the 'veil' produced by the sensorial knowledge of creation and the knowledge of God's glory, with the 'uncovered face' of the mind, that is, accompanied by an ignorance of the sensible world, yet not a complete ignorance, but one that admits temperate,

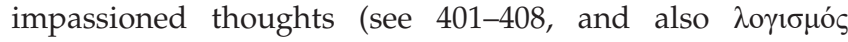

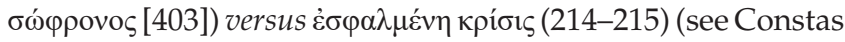
2018:90-91, no. 65, 66).

Certainly, this relationship with the Creator is inevitably diminished in the postlapsarian condition, but even here, although he seems to assign the same negative value to caring for the body ( $\left.\varphi \rho \operatorname{lov}^{\prime} i \zeta \omega\right)$, as for the affection for it

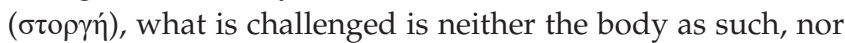
every care for it, but again the exclusive concern, knowledge and love reduced to the relationship with the material self as a substitute of the relationship with God, which is philautia precisely, and it is this one considered the object of liberation (Constas 2018):

[T] he total denial of the soul's affection for the body and this world. Through this denial, we cast off the desire for pleasure and

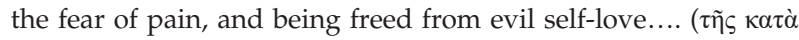

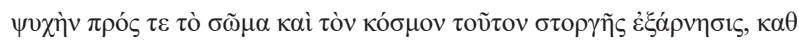

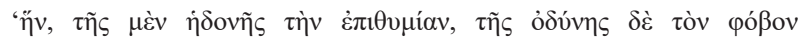

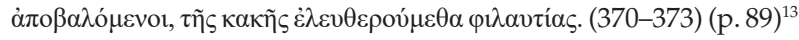

According to this reading, however, some ambiguities remain. Although ignoring the Cause appears as the initial moment of the fall, followed by the orientation towards the sensible ('ignorance, the most initial source of all evils'; $\tau \tilde{\eta} \varsigma$

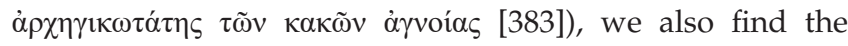
inverse suggestion: 'to those who partake of it corporeally it

13.The very use of the same term philautia for good self-love allows the inclusion of the body, as well as of the whole visible creation, in the fulfillment of the human being in the love of God as his own response to His love for His entire creation. It is also worth noting that he avoids here the use of oxżoc (relation), repeatedly present in the epistolary part of the Introduction (e.g. 162,165) and the rest of QT opting for otopyń (love, attachment); see Bieler (2019:124-145). St. Maximos has little to say here of a positive role of the human body; see, however, the first phrases of the OT Intr where he praises his addressee, Thalassios, whose flesh 'thrases of the QT Intr where he praises his addressee, Thalassios, whose flesh 'through ascetic practice and proper conduct', received 'the glory' of his virtuous soul (Constas 2018:73), a descending manifestation that accompanies the elevation of the mind to the Creator, treated more broadly in Ambiguum 7, fo example. On the relationship between soul and body, see recently Bieler (2019.124-145); on the place and function of the body in Maximos' overall theology, see Cooper (2005). I thank one of the anonymous reviewers for drawing my attention to this point. becomes the teacher of passions, making them oblivious to

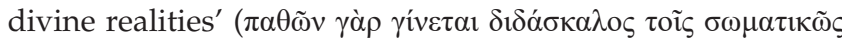

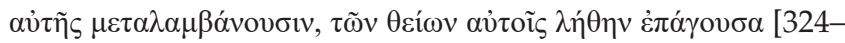
325]; [Contas:87]). Also, although the disorientation towards the creation seems to precede the pathological self-orientation (circuits 2, 3, 4, respectively, 5), there is also the opposite suggestion ('which we came to know through the sensory

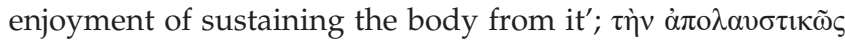

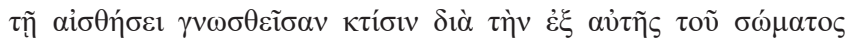

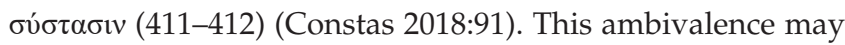
be an expression of the identified causal circularities and the difficulty of establishing the initial moment (other than by ad litteram accepting the succession in the Genesis account of the episode). At the same time, we may consider that, for Maximos, the ignorance of the Cause, the exclusively sensorial knowledge of reality, and the anxious recognition and love of oneself are simultaneous, as three dimensions of a single reality that is the fallness.

\section{The genetic mechanism}

Another reason for the ambiguity regarding the priority within the circular causal bonds may come from the distinction between Adam's experience of the fall and that of his descendants. Maximos seems to assume, in fact, the structural identity of these experiences (e.g. the expression 'always [ácí]) eating from the tree of disobedience' ([Constas 2018:86]) cannot refer only to Adam). Or he does not? As we saw above, in the second definition of evil he introduces the level of survival, of course, relevant to Adam after the fall, too. Or, as descendants of Adam, we start our existence not from his original, incorruptible state, but from where he ended, namely from his fallen, 'corruptible and subject to dissolution' condition. Therefore, it is plausible, in our case, to identify at the origin of the mechanisms of fallness, not the ignorance of the Creator, but the very sensorial experience and knowledge captured by the dialectic of pleasure and pain, which give rise to philautia, and which covers the mind with the veil of ignorance of the divine realm, imperceptible to sensation. But even in this case, at least from one point onward, the order of initiating the circuits no longer matters; the enslaving result of their operation is the same.

We encounter here the famous problem of the transmission of the fallness, and what is remarkable in this text is that it is not treated, but only passingly evoked in each of the two definitions, in both cases in proximity with the pleasure-pain dialectic (Constas 2018):

$[T]$ hus the great and innumerable mob of passions was introduced

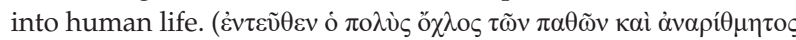

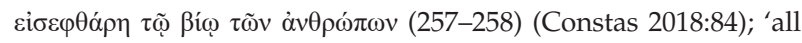
the impurity of evil was introduced into human life in many different ways and in manifold forms ... since all who share in

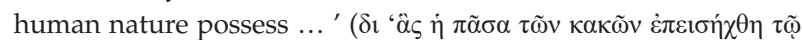

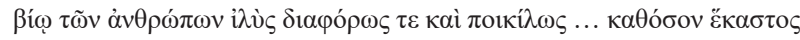

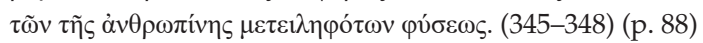

Maximos will broadly resume in QT 21 and QT 61 the same explanation of the origin of evil and the fall in both of their 
aspects, the survival and the passions with the pleasure-pain dialectic (without, however, resorting to philautia). There, the generational succession from Adam plays an explicit role in the regime of death and sin and the dominion of the devil, both of which tyrannises the humans. A careful comparison between the three texts illustrates very well his circular and yet non-repetitive way of thinking: in all three places, the characters are practically the same (Adam, his heirs, the devil, Christ), the unfolding of the plot almost identical (Adam failed and we inherit from him the fallen condition, which is assumed by Christ who frees us all), but their immediate purpose and, as such, the details are different. Of course, there are different places in the Bible interpreted, but Maximos seems to take advantage of the hermeneutic variety to examine the same subject from different perspectives. If in QT 21, in the foreground is the deception by Christ of the strategies by which the devil seeks to lose humans by speculating on the passibility of their fallen condition ( $\tau$ ò $\pi \alpha \theta \eta \tau o ́ v)$ and the pleasure-pain mechanism as its manifestation, in QT 61, in the foreground there are the two ways of originating of the postlapsarian human existence, namely the bodily and passionate birth, according to Adam, and its overcoming through the spiritual birth, accompanied by the overthrow of the meaning of suffering and death, in Christ. In both Responses, we can identify a phylogenetic mechanism of generational transmission of the fallness, and an ontogenetic mechanism, that is, its personal reactivation, the two supporting each other. The phylogenetic mechanism is in the spotlight in QT 61, while the ontogenetic one is in the QT 21; correlated with this different focus, the origin of ontogenesis appears in QT 61 in the epicenter of pleasure, while in QT 21, somewhat less clearly, in the epicenter of pain.

By comparison, QT Intr is closer to QT 21, precisely by blurring the phylogenetic aspect and emphasising the ontogenetic one. But, unlike QT 21, where the experience of pleasure and pain seems, at first sight, separate, ${ }^{14}$ in $Q T$ Intr precisely their mutual coupling and, especially, the coupling between the cognitive and the affective circuit, around the sensorial experience and philautia - almost absent in QT 21 are central. The emergence and permanent manifestation in the fallness - both as an event and as a subsequent condition of a composite and lethal knowledge, which produces the

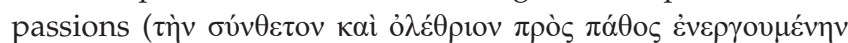

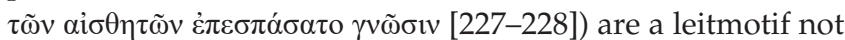
only of this Introduction but also of the Responses in general and even of the whole opera..$^{15}$ The content of this knowledge is exactly the cognitive-affective-somatic coupling described in the first definition. The causal circularity of the connections between the three components of the human constitution determines the self-destructive character of this (dis) functional coupling, which plays in Maximos the role of a

14.The first temptation, by pleasure, takes place at the beginning of Christ's activity; the second, by pain, at its end.

15.In the Introduction, direct or indirect references to composite knowledge appear also in the lines $7-9,20-23,131-144,235-243,265-266,295-296,313-314$ $321-322,324-326,364-367,380-381$. Other important occurrences in QT 16, 49, $321-322,324-326,364-367,380-381$. Other important occurrences in QT 16, 49,
$54,55,62,64,65$; this theme is pervasive in Capita de caritate; see Dimitrova (2016). true genetic mechanism of the perpetuation of the fallness. A more complete demonstration presupposes an equally detailed examination of the other relevant occurrences, but what we can already say is that through this mechanism the fallness is self-sustaining in all its components. ${ }^{16}$

\section{An emotional disorder}

The comparison with QT 21 and QT 61 is relevant for another reason. If in QT 21, the main affective determinant of passion as the engagement of the volition from what is 'according to nature' (even the one affected by the fall) to what is 'against nature' - appears to be the pain, ${ }^{17}$ in QT 61 the main determinant is pleasure, because pain (suffering and death) plays a new, positive role, by voluntary assumption, both by Christ and by Christians. In QT Intr, in contrast, the two affective experiences play an equal motivational role. But, again, the three texts are different in their involvement of the other main pair of emotions that are lust and fear: lust is blurred in QT 21 (but can be assumed) and is missing from QT 61; in turn, fear - as fear of death (Heb 2:15) - plays an important role in QT 21, but in QT 61 it appears only once; instead, in our text, both are present to the same extent.

Numbered together with pleasure and pain (here grief, $\lambda v i \pi \eta)$ immediately after our text, in QT 1 - which can be read as a welcome addition to the two definitions - lust (here $\dot{\varepsilon} \pi \imath v \mu$ ía, but often $\pi$ ó $\theta$ os, in other places) and fear ( $\varphi$ ó with the first pair, pleasure and pain, the fundamental emotions ( $\tau \grave{\alpha} \pi \dot{\alpha} \theta \eta)$ in Maximian psychology, that is, the most general modes of the postlapsarian manifestation of the powers corresponding to the 'most irrational part of nature',

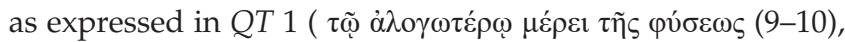

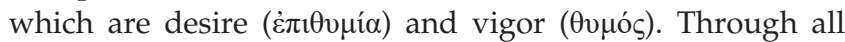
four emotions and those that derive from them, not only through pleasure and pain, the resemblance to irrational creatures specific to fallen existence becomes evident, says Maximos. What this means is the theme of another answer, QT 43, where he resumes the interpretation of the Tree of Disobedience. Affects appear there in connection with the functions of the body, as mechanisms of psycho-somatic

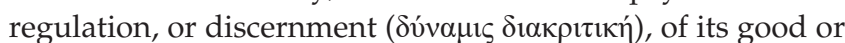
bad state. Of interest to us, the four emotions are coupled in two ways: according to time, in a pair that expresses affective states of anticipation (lust, fear) and a pair that expresses affective states of realisation (pleasure, pain); according to the content of gratification, in a pair that expresses states of satisfaction (lust, pleasure) and another that expresses states of dissatisfaction (fear, pain) (see also Ambiguum 10.44).

In this sense, even when Maximos seems to speak only or mainly about the pair of pleasure and pain, we can assume that he also considers the associated pair of anticipation, lust and fear. Our text confirms this in an interesting way.

16.The mechanism is quite visible, for example, in $Q T 62$ and $Q T$ T. 65 . Graphically similar schemes with Figure 2 can summarise $Q T$ T21, 42, 61 and Ambiguum 42 and similar schemes with Figure 2 can summarise QT 21, 42,61 and Ambiguum 42 and in all of them one can identify the place of the genetic mechanism. Of course, the whole ascetic and spiritual engagement of praxis cum theoria is opposing this
composite circuitry (see Larchet 1996; Steel 2012; Streza 2013).

17.Because the last temptation, by pain, is the decisive one; also, the fear of death plays a major, although not unique, motivational role in QT 21. 
By talking about the experience of fallness, Maximos usually refers directly to pleasure and pain, and when it comes to the soteriological aspect, he usually mentions them with their anticipatory pair (Constas 2018):

[W]e cast off the desire for pleasure and the fear of pain. ( $\tau \tilde{\eta} \varsigma \mu \dot{\varepsilon} v$

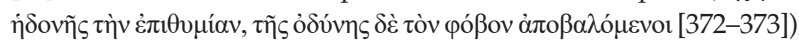
(Constas 2018:89); 'whoever does not desire bodily pleasure and has absolutely no fear at all of pain has become dispassionate'.

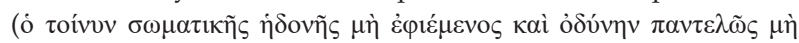

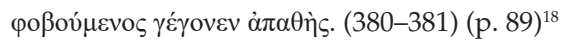

It is also in the context of anticipation that the devil is mentioned here. The first time, at the beginning of the first definition, the evil one manages to disorient the human

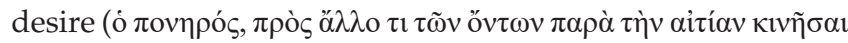

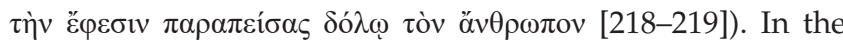
second mention, the evil appears together with the

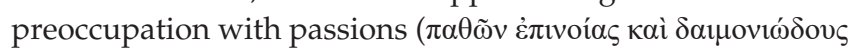

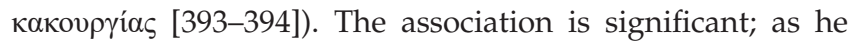
explains in QT 21 but also in other places (QT 26, 50, 54), in order to lead humans to his ends, the devil takes advantage of both the desire for pleasure and the fear of pain. We can assume that even when the devil is directly associated with pleasure and pain, as far as he does not produce them directly, also at stake for Maximos are the anticipatory emotions, especially because the devils' work is par excellence temptation. ${ }^{19}$ In any case, the explicit mention of the anticipatory emotions lust-fear in the soteriological context suggests that the circular dialectic pleasure-pain must be disassembled from this level on.

\section{Conclusion}

If the interpretation proposed here can be accepted, what $Q T$ Intr offers us are not just definitions of evil, but the identification of a genetic mechanism involved in both the phylogenetic transmission of the fall and its ontogenetic reactivation. In fact, there are no two definitions, but two 'zoom-in' approaches, both on the cognitive-affective-somatic coupling in the condition of fallness, the difference being given by the fact that the first focus is more phenomenological - it identifies the circular mechanism and its behavioural manifestations so present in our lives - and the second is more aetiological, explaining why this mechanism emerges and lasts, despite its catastrophic results.

The French patrologist Jean Claude Larchet considered that in the Pauline expression about Christ who 'was made sin for us' (2 Cor 5:21), commented upon by Maximos in QT 42, there it operates a metonymy (see Constas 2018:242, note 5). What I suggest at the end of this investigation is that

18.See also (351-352). Anticipation also comes indirectly, when he speaks of the pursuit of pleasure and the flight from pain, as well as of the invention of passions. On affectivity overall, see Blowers $(1996,2013)$ and Summerson $(2020)$. The last author's approach is focused on the pair fear and grief/pain, in line with Maximos' own suspicious, ascetical treatment of the hedonistic pair desire/lust and pleasure.

19.The corresponding Greek, $\pi \varepsilon \tilde{\rho} \alpha$, allows for a mental or affective anticipation and an actual experience as well; see this ambivalence in the Introduction (127-133), where imagination and anticipation of pleasure and pain are motivational drivers; note the ambiguity of the whole passage between passions and demons, both grammatically readable; see Constas (2018:78, no. 24). For the notion of grammatically readable; see Constas (2018:78, no. 24). For the notion of
experience, see Miquel (1989). On the neglected topic of demonology in Maximos, see Constas (2018:22, note 61) metonymy is a method frequently used by Maximos himself. At least in the case of the pleasure-pain pair, whenever he invokes it, we can assume that he is considering both of the coupled affective pairs. Moreover, whenever he directly or indirectly evokes the transmission of the fallness (as in QT 21, $42,43,61,62$ but also in works considered from the same period, such as Ambigua and Expositio orationis dominicae, and later works), and regardless of which of its aspects are highlighted, phylogenetic or ontogenetic or both, we can assume that he also minds the genetic mechanism described in the text analysed here. What he emphasises, blurs or omits from this mechanism in its various occurrences in his writings is highly significant and may be an important heuristic tool to better understand his interpretive technique, the arguments used and their theological and spiritual-moral concern. For the research regarding the relationship between addictions and passions, this mechanism is relevant as a Patristic compeer of what contemporary psychology calls affect dysregulation (see Garland et al. 2020) and which plays a noted role in addictions. But it is the theme of another work, still in progress.

\section{Acknowledgements Competing interests}

The author declares that he has no financial or personal relationships that may have inappropriately influenced him in writing this article.

\section{Author's contributions}

S.M. is the sole author of this article.

\section{Ethical considerations}

This article followed all ethical standards for research without direct contact with human or animal subjects.

\section{Funding information}

Project financed by Lucian Blaga University of Sibiu research grants LBUS-IRG-2018-04.

\section{Data availability}

Data sharing is not applicable to this article as no new data were created or analysed in this study.

\section{Disclaimer}

The views and opinions expressed in this article are those of the author and do not necessarily reflect the official policy or position of any affiliated agency of the author.

\section{References}

Bieler, J., 2019, Der Einheitsbegriff als Kohärenzprinzip bei Maximus Confessor, Brill, Leiden.

Blowers, P.M., 1996, 'Gentiles of the soul: Maximus the Confessor on the substructure and transformation of human passions', Journal of Early Christian Studies 4(1), 
Blowers, P.M., 2013, 'Aligning and reorienting the passible self: Maximus the Confessor's virtue ethics', Studies in Christian Ethics 26(3), 333-350.

Constas, M., 2018, St.: The responses to Thalassios, The Catholic University of America Press, Washington, DC.

Cook, C.C., 2006, Alcohol, addiction, and Christian ethics, Cambridge University Press, Cambridge.

Cook, C.C., 2012, The Philokalia and the inner life: On passions and prayer, Wipf and Stock Publishers, Eugene, OR.

Cooper, A.G., 2005, The body in Maximus the Confessor: Holy flesh, wholly deified, Oxford University Press, Oxford.

Dimitrova, N., 2016, Human knowledge according to Saint Maximus the Confessor, Wipf and Stock Publishers, Eugene, OR.

Garland, E.L., Bell, S., Atchley, R. \& Froeliger, B., 2020, 'Emotion dysregulation in addiction', in T.P. Beauchaine \& S.E. Crowell (eds.), Oxford handbook of emotion dysregulation, pp. 313-326, Oxford University Press, Oxford.

Larchet, J.C., 1996, La divinization de l'homme selon saint Maxime le Confesseur, Cerf, Paris.

Larchet, J.C., 1998, 'Ancestral guilt according to St. Maximus the Confessor: A bridge between eastern and western conceptions', Sobornost 20(1), 26-48.

Maxime le Confesseur, 2010, Questions à Thalassios (1-40), Sources chrétiennes 529, Éditions du Cerf, Paris.

Miquel, P., 1989, Le vocabulaire de l'expérience spirituelle dans la tradition patristique grecque du IVe au XIVe siècle, Editions Beauchesne, Paris.

Moldovan, S., 2013, 'Ministry, philanthropy, social services? The church and the challenge of addictions', Revista Teologică 95(1), 157-177.
Moldovan, S., 2016, 'Addictions and orthodox spirituality: Towards a model of human behavior', Teologia 69(4), 28-43.

Moldovan, S., 2018, 'Can Patristic passions help us understand and cure our addictions? A reading of St. Maximus the Confessor', Studia Monastica 60(2), 281-294.

Oancea, C.H., 2021, 'The trees in the middle of Paradise (Gn 2:9) during the Great Lent: Orthodox hymnography as biblical interpretation', HTS Teologiese Studies/ Theological Studies 77(4), a6699. https://doi.org/10.4102/hts.v77i4.6699

Pauline, A. \& Bronwen, N. (eds.), 2015, The Oxford handbook of Maximus the Confessor, Oxford University Press, Oxford.

Steel, C., 2012, 'Maximus Confessor on theory and praxis: A commentary on Ambigua Ad Johannem VI (10) 1-19', in T. Bénatouïl \& M. Bonazzi (eds.), Theoria, praxis, and the contemplative life after Plato and Aristotle, pp. 229-257, Brill, Leiden.

Streza, C., 2013, 'Saint Maximus the Confessor's Mystagogia - A complex liturgical commentary', International Journal of Orthodox Theology 4(1), 63-82.

Summerson, A.J., 2020, Divine scripture and human emotion in Maximus the Confessor, Brill, Leiden.

Thunberg, L., 1995, Microcosm and mediator: The theological anthropology of Maximus the Confessor, 2nd edn., Open Court, Chicago, IL.

Trader, A., 2011, Ancient christian wisdom and Aaron Beck's cognitive therapy: A meeting of minds, Peter Lang, New York, NY.

Von Schönborn, C., 1982, 'Plaisir et douleur dans l'analyse de saint Maxime d'après les Quaestiones ad Thalassium', in F. Heinzer \& C. Von Schönborn (eds.), Maximus Confessor: Actes du Symposium sur Maxime le Confesseur, Fribourg 2-5 septembre 1980, pp. 273-284, Editions Universitaires, Fribourg. 